\title{
Los "Períodos Intermedios" en la historia y en la historiografía del Antiguo Egipto
}

\author{
Q Roxana Flammini \\ Consejo Nacional de Investigaciones Científicas y Técnicas / Universidad Católica Argentina, \\ Argentina
}

Fecha de recepción: 8 de junio de 2019. Fecha de aceptación: 5 de julio de 2019.

\begin{abstract}
Resumen
Los denominados "Períodos Intermedios", calificados por la historiografía tradicional como épocas "oscuras", de decadencia, revolución o anarquía, fueron descriptos en contraposición a los procesos donde el Estado mantuvo la unidad y el alcance sobre el territorio egipcio, al menos desde Elefantina al Delta. Por cierto, su denominación a través de un orden numérico y su calificación como "intermedios" sugiere cierta semejanza y orden secuencial que está muy lejos de lo que evidencia la documentación. En esta aproximación procuraremos diferenciar las premisas -compartidas o no- que subyacen en la base de las interpretaciones de tales períodos, cuáles son los denominadores comunes y cuáles las singularidades que definen cada uno de estos lapsos disruptivos.
\end{abstract}

\section{The "Intermediate Periods" in the Ancient Egyptian History and Historiography}

\begin{abstract}
The so-called "Intermediate Periods" were traditionally described as "dark ages," times of decay, revolution or anarchy, opposite to the historical processes where the State was unified and sustained the control over the Egyptian territory, at least the core which extended from Elephantine to the Delta. Furthermore, their naming through a numerical order ("First," "Second," and "Third") as well as their qualification as "Intermediates" suggests certain similarity and sequential order which are far from the facts proven by the evidence. The aim of this work is differentiating the underlying premises lying beneath the analyses of such periods, the common factors detected and the singularities which define each of these disruptive processes.
\end{abstract}

Palabras clave

historiografía Egipto antiguo Períodos Intermedios prácticas sociales
Keywords

historiography ancient Egypt Intermediate Periods social practices 
1. Incorporaremos aquí una breve definición de lo que se entiende por Estado en el contexto de este trabajo, alejada por cierto de las definiciones que hacen al Estado Moderno. Para sintetizar-dado que las discusiones acerca del concepto y la propiedad o no de su uso aplicado a sociedades premodernas es tema de debate- seguiremos a Norman Yoffee (1993: 69), cuando señala que "la condición suficiente más importante y necesaria que separa Estados de noEstados es la emergencia de ciertos roles socioeconómicos y gubernamentales que están emancipados del parentesco real o ficticio".

\section{Introducción}

Como puede observarse en cualquier manual de la especialidad, la historiografía dividió la prolongada historia del Egipto dinástico en períodos bien diferenciados en torno a la unidad o "colapso" del Estado. Así, si tomamos como punto de partida su emergencia sobre fines del IV milenio a.C., la secuencia está conformada por el Dinástico Temprano, el Reino Antiguo, el Primer Período Intermedio (III milenio a.C.); el Reino Medio, el Segundo Período Intermedio y el Reino Nuevo (II milenio a.C.) y el Tercer Período Intermedio y la Baja Época (I milenio a.C.). Como es fácil advertir, la secuencia enfatiza los períodos de unificación al distinguirlos entre sí con los adjetivos Antiguo, Medio y Nuevo, dejando en medio de éstos, precisamente, a los Períodos Intermedios, distinguidos únicamente por una calificación numérica ordinal (Primero, Segundo y Tercero, desde aquí PPI, SPI y TPI respectivamente). Esta simple observación revela que el énfasis estuvo puesto, al menos en el momento de la generación de esta periodización -sobre fines del siglo XIX (Meyer, 18841902) - en los momentos en que el Estado estaba concentrado en manos de una realeza que gozaba de la suficiente legitimidad como para mantener la cohesión interna. ${ }^{1}$ No es casualidad que esta periodización haya emergido en el siglo XIX en la Europa occidental, que vio nacer y consolidar el paradigma de la Modernidad con sus pilares basados en los conceptos de orden y progreso y los "estados-nación" (Koselleck, 2004: 17; White, 2002: xiv). Es así que esa imagen del Estado egipcio unificado es la que se transformó, a su vez, en paradigma canonizado de la incipiente Egiptología, contra el cual se contrastó el devenir histórico de esa sociedad. De este modo, todo proceso que no se ajustara a tal paradigma resultaba pasible de ser considerado corte y desviación de lo que "verdaderamente" era el antiguo Egipto.

En consecuencia, los períodos que mostraban el "cénit de la civilización egipcia", como los Reinos Antiguo -con sus eternas pirámides- y Nuevo -signado por el reinado de una mujer (Hatshepsut), las particularidades de la religión amarniana, las maravillas halladas en la tumba de Tutankhamón y la épica de Ramsés II-, gozaron de la atención privilegiada de los investigadores. Ciertamente, la discusión sobre la datación de la narrativa del éxodo bíblico en este último período no debería excluirse de este listado. Entre ellos quedaba, como su denominación lo indica, el Reino Medio, más tarde "reivindicado" por la producción literaria que lo distingue. No podemos afirmar que sucedió algo semejante con los períodos donde convergieron ciertos procesos disruptivos. Si ahondamos en su denominación obtendremos pistas sobre su concepción, que no nos parecen ociosas en modo alguno: las denominaciones guardan un paralelo entre cómo algo es concebido y los atributos que se le otorgan. Por cierto, eso no significa que desde aquí pretenda algo tan poco útil -y hasta soberbio- como sería revisar esa terminología. Mi objetivo es mucho más limitado: pretendo reflexionar sobre los paradigmas que se ocultan detrás de una simple denominación, detectar algunas premisas subyacentes, y verificar la posibilidad de distinguir diversas prácticas sociales que se visualizan en la disrupción.

Como ya señalamos, estos procesos son identificados por una numeración ordinal ("Primero", "Segundo" y "Tercero") lo que indica, per se, que se trata de una secuencia definida. De hecho, los números ordinales indican la posición 
que ocupa un elemento en una sucesión ordenada. Aquí tenemos entonces un elemento a señalar, ya que se trataría, en todo caso, de una sucesión ordenada de tiempos miserables y calamitosos, alejados del Egipto paradigmático. El segundo elemento que compone la denominación nos sigue dando pistas sobre la lectura que se hizo de estos procesos al momento de identificarlos. Se habla de "período", es decir, de una unidad temporal. Pero una de sus definiciones, según la RAE, refiere al "tiempo que algo tarda en volver al estado o posición que tenía al principio". Es quizás ésta la que mejor se ajusta a la concepción que se encuentra detrás de esta denominación, algo con lo que, paradójicamente, los antiguos egipcios estarían de acuerdo.

Finalmente, todos ellos reciben la condición de "intermedios", es decir, son definidos por una condición externa -el estar en medio de los períodos de "unidad"- con lo cual se transformaron en repositorios de definiciones afines a la idea de "colapso" entendido como una subversión total del statu quo: de este modo, se consideraron épocas "oscuras" por su difícil reconstrucción histórica; ${ }^{2}$ de sangrientas "guerras civiles"3 o de "revolución social"; ${ }^{4}$ o bien "anárquicas" por el estilo que asumieron ciertas prácticas políticas. ${ }^{5} \mathrm{Si}$ bien en tiempos más recientes tales definiciones se vieron moderadas al asignárseles el concepto de "crisis", la idea de quiebre cuasi total no fue del todo revertida, convirtiéndose en una premisa sostenida por largo tiempo. Sin embargo, ningún "colapso" por más extendido que esté llega a ser total y mucho menos homogéneo. Notoriamente, la secuencia de dinastías no desapareció: puede ser trazada desde la emergencia de la época dinástica hasta su fin. Sin embargo, si a esa idea de colapso generalizado se le suma que, como ya fue señalado, la historiografía discriminó a esos períodos numéricamente, se les podría asignar no sólo la posesión de características comunes, sino secuenciales. Así, constituirían un crescendo de sucesos calamitosos extendidos.

Precisamente, las ideas que sostiene J. Taylor (2003 [2000]: 324) al iniciar su apartado sobre el TPI en The Oxford History of Ancient Egypt podrían caberle indistintamente a cualquiera de los períodos intermedios:

Esta etapa se caracteriza por unos cambios significativos en la organización política, la sociedad y la cultura de Egipto. El gobierno centralizado fue sustituido por la fragmentación política y la reaparición de centros locales de poder; un flujo permanente de extranjeros (...) modificó de forma permanente el perfil de la población, mientras Egipto en su conjunto se volvió más introspectivo y sus contactos con el mundo exterior (sobre todo su impacto sobre el Levante) se redujeron en escala. ${ }^{6}$

Como se puede observar, rondan sobre estas cuestiones: pérdida de la centralización y consecuente fragmentación política; emergencia de los centros locales; llegada de extranjeros y reducción de los contactos con el exterior. A ello podríamos adicionar la omisión de los reyes de estos períodos en algunas listas reales conservadas, o en todas, dependiendo de la situación histórica en cuestión. Ahora bien, si definir los rasgos comunes parece tarea bastante sencilla, remarcar la singularidad de cada uno de esos procesos, y reevaluar las diversas evidencias con las que se los suele describir, es algo más complejo.
2. Bell (1971: 1-2) distingue dos "edades oscuras" en el Cercano Oriente Antiguo que en Egipto coinciden con el PPI (ca. 2200 a.C.) y con la crisis de ca. 1200 a.C. luego de la cual Egipto comienza una "prolongada declinación". Propone hallar una "realidad histórica" que se encuentre en la base de tales procesos políticos y así, para la primera "edad oscura" sostiene razones de índole climática, específicamente una sequía, como problema de origen. 3. Cf. Campagno, 2013.

4. Una de las lecturas más habituales, cf. Rosell, 2015. 5. En palabras de Ritner (2009: 1), quien enfatiza la cuestión étnica: "Caracterizado por la creciente fragmentación política bajo gobernantes definidos de modo variado como sacerdotes-reyes, grandes generales y jefes de linaje, el TPI es denominado despectivamente como la "anarquía líbica", en referencia a la etnicidad de sus gobernantes extranjeros, que descendían de mercenarios libios". La traducción me pertenece.

6. La traducción me pertenece. 
Para afrontar tales cuestiones es necesario desentrañar los supuestos básicos sobre los que cobraron forma los estudios sobre los períodos intermedios. Aquí, mencionaremos dos. Al primero de ellos le dedicaremos unas reflexiones un tanto más detalladas en el próximo punto; en cuanto al segundo, optamos por incluirlo, en caso de ser pertinente, en el apartado referido a cada período intermedio. Así distinguimos: a) la explicación de tales procesos a través de la aplicación directa de la información provista en documentos mucho más tardíos (dado que durante mucho tiempo no hubo a disposición evidencias contemporáneas suficientes) y b) el rol significativo que tradicionalmente se le asignó a las "causas subyacentes y únicas", como las variables externas (por ejemplo, las crisis climáticas y/o las invasiones extranjeras) en el colapso del Estado unificado.

De esta manera, y como ya se mencionó, los rasgos generales que comparten esos lapsos disruptivos son muy pocos, y podrían enumerarse, de modo algo más extendido, del siguiente modo: a) la falta de una estructura gubernamental centralizada que ejerciera el control sobre el territorio donde tradicionalmente regía ma’at, en términos generales, desde Elefantina en el sur al Mar Mediterráneo al norte; b) la emergencia, discontinuidad o reformulación de diversas prácticas sociales subyacentes; c) la aparición de rasgos culturales locales y d) la reconfiguración (y no sólo reducción) de los contactos con el exterior. Por cierto, se trata de características sumamente relevantes de por sí para ser analizadas, pero que adquieren su propia dimensión y singularidad en cada uno de tales procesos. Cabe señalar del mismo modo las dificultades que entraña la evidencia disponible: a) no todo el territorio fue excavado en igual proporción; b) no todos los ámbitos permiten conservar evidencias en buen estado; y c) ciertas evidencias recuperadas en buen estado se deterioraron por problemas de conservación (por ejemplo, el Papiro Real de Turín, cf. Ryholt, 2004).

De este modo, en este recorrido proponemos abordar las singularidades que se visualizan en los "períodos intermedios" a la luz de las evidencias disponibles hoy en día, partiendo de las siguientes premisas: a) que cada una de estas situaciones socio-históricas fue precedida por lapsos prolongados de unidad y centralización estatal y b) que Egipto, como entidad socio-histórica, fue integrándose de modo paulatino, pero irreversiblemente, a las extensas redes de intercambio en sentido amplio (de bienes, personas, ideas, creencias y tecnologías) que atravesaban el Cercano Oriente Antiguo, conectando el noreste de África con Asia Occidental y el Mediterráneo Oriental a la vez que también pasó de detentar un rol central (III y II milenios a.C.) a uno periférico (I milenio a.C.).

\section{Algunas reflexiones sobre el uso de documentación tardía para explicar las dinámicas de procesos de descentralización del Estado en el antiguo Egipto}

Es empíricamente comprobable que las situaciones socio-históricas que se desencadenaron a fines de las Dinastías VI, XII y XX constituyeron períodos disruptivos en la existencia de un Estado concebido como el ámbito de regencia 
de un único rey-dios, y por lo tanto, unificado: toda situación de descentralización fue rememorada y evocada desde lo ideológico como un lapso dominado por las fuerzas del temido caos.

Sin embargo, una lectura literal de ciertas narrativas posteriores y la trasposición directa de las situaciones descriptas en ellas a circunstancias históricas precisas, no sólo desdibujaron las particularidades de cada uno de tales procesos, sino que tendieron a cerrar el debate sobre otras variables posibles por la fuerza de su predominio, incluso una vez que fue encontrada evidencia contemporánea.

De este modo, las narrativas originadas durante el Reino Medio que refieren la precedencia de una época de caos (fundamentalmente textos compilados bajo el rótulo de "literatura pesimista"), influenciaron sustancialmente en las lecturas académicas sobre el PPI, ${ }^{7}$ aunque las evidencias contemporáneas no hicieran referencia a algún tipo de situación caótica extendida, salvo el tema de las hambrunas que es recurrente en las biografías de los líderes locales del Alto Egipto pero que, como luego veremos, puede ser interpretado de un modo alternativo. Narrativas más tardías como las Lamentaciones de Ipu-ur (Pap. Leiden I 344), o las Lamentaciones de Jajeperraseneb (EA 5645), ${ }^{8}$ transitan por una descripción muy precisa de la alteración del orden por el caos, bajo la forma de una subversión de las pautas sociales habituales. Sin embargo, como sostiene J. Cervelló Autuori, estas últimas narrativas refieren "al tópico de la 'sociedad ideal' presentada por inversión polar de sus características", mientras que $\mathrm{La}$ Profecía de Neferti (Pap. Hermitage 1116B y Ostracon Petrie 38 - UC 39637) ${ }^{9}$ “insiste más en la dimensión cósmica del caos" (Cervelló Autuori, 1996: 193). Estos textos, entonces, tendrían más que ver con la materialización, en forma de narrativa, de antiguas creencias relativas a la subversión del "orden por el caos" -el "cosmos al revés" (Cervelló Autuori, 1996: 192)- y no a una descripción de "lo fáctico", que estaría muy alejada de la concepción del pasado que tenían los antiguos egipcios. ${ }^{10}$

Hechas estas salvedades, el impacto que significó la disrupción también se puede visualizar a través de documentos de otro orden, también tardíos, como lo son las listas de reyes. Un acontecimiento preciso, como el traslado de la capital de Menfis a Heracleópolis, significó un quiebre relevante: dos listas datadas en la Dinastía XIX -el Papiro de Turín y la lista real de Abidos- dan pistas sobre esta situación. La primera inserta una sumatoria que reúne los reinados del antiguo Egipto luego de la lista de reyes de la Dinastía VIII; mientras que la segunda no da nombres de reyes entre la Dinastía VIII y el inicio del Reino Medio (Seidlmayer, 2003:108).

Como hemos visto, las evidencias datadas posteriormente al PPI muestran que ese período fue considerado como un lapso disruptivo y complejo por generaciones posteriores, pero reitero, a riesgo de ser redundante: algo muy distinto es transferir automáticamente las descripciones que brindan las narrativas tardías a la época a la que se refieren.

Algo semejante sucede con las evidencias de este tipo a las que se podría vincular con el SPI (ca. 1800-1530 a.C.), situación disruptiva donde la característica sobresaliente está dada por la primera dominación extranjera en territorio
7. Para mayor detalle sobre las lecturas historiográficas realizadas sobre el PPI, cf. Campagno, 2013.

8. Existen innumerables trabajos dedicados al análisis de estos textos, desde diversas perspectivas. Aquí mencionaré a título ilustrativo los siguientes: para las Lamentaciones de Ipu-ur, Gardiner, 1969 [1909]; Lichtheim, 1973: 149-163; Tobin, 2003 [1973]; Enmarch, 2008. El texto original dataría de la Dinastía XIII, mientras que la copia proviene posiblemente de tiempos de la Dinastía XIX. En cuanto al texto de las Lamentaciones de Jajeperraseneb, el mismo se encuentra escrito sobre una tablilla de madera hallada en Tebas, hoy en el Museo Británico. Fue datada en la temprana Dinastía XVIII, mientras que la composición, fue ubicada entre fines de la Dinastía XII e inicios de la XIII a través del análisis de la lengua. Cf. Wilkinson, 2017: parte 4. Cf. también Lichtheim, 1973: 145-149.

9. Para La Profecía de Neferti, cf. Helck, 1970; Lichtheim, 1973: 139-145.

10. Para una aproximación al PPI en base a documentación del período y no desde la producción literaria del Reino Medio, cf. Spalinger, 2008. 
11. Nuevamente, existen innumerables trabajos sobre estos textos. A título ilustrativo mencionaré, para la Inscripción del Speos Artemidos, cf. Allen, 2002; para la Disputa entre Apofis y Seqenenra, cf. Spalinger, 2010.

12. Actualmente existen tres estelas de este rey, todas halladas en el templo de Amón en Karnak que refieren a las luchas de finales del SPI. De la Primera Estela se recuperaron dos fragmentos, publicados por Lacau (1939), y existe una copia hierática probablemente algo más tardía, conocida como la Tablilla I de Carnarvon (Gardiner, 1916). La Segunda Estela es la mejor conservada, hoy se encuentra en el Museo de Luxor bajo la nomenclatura J.43 (cf. Habachi, 1972; Smith y Smith, 1976; Goedicke, 1995). Los fragmentos de la Tercera Estela fueron identificados y publicados mucho más recientemente (Gabolde, 2005; van Siclen III, 2005, 2010). 13. Desde la localización al presente se publicaron innumerables trabajos sobre los hallazgos. A título ilustrativo, cf. Bietak, 1996. propiamente egipcio. Los hicsos al norte (con centro en Avaris, en el extremo más oriental del Delta, cuyo control se extendió hasta Cusa) y los nubios al sur (con centro en Kerma, que controlaron la Baja Nubia hasta Elefantina, poniendo bajo su órbita las fortalezas egipcias erigidas durante el Reino Medio) significaron una ruptura de otro orden: si bien el PPI significó la posibilidad de ser leído como la presencia efectiva de las fuerzas del caos a través de la fragmentación política del Estado y la independencia de los nomarcas del Alto Egipto, en el SPI tales fuerzas encarnadas en los extranjeros efectivamente controlaron parte del territorio egipcio aglutinadas en torno a la dinastía de los hicsos. La potencia rememorativa que tal situación produjo posteriormente es destacable.

Por cierto, hasta el descubrimiento de las estelas de Kamose (último rey de la Dinastía XVII, ca. 1555-1550 a.C.) y la localización de la antigua capital de los hicsos, Avaris, en Tell el-Dab’a, se consideraba que una "invasión” desde el Este había causado la catástrofe, documentada por textos muy posteriores a los acontecimientos como los epítomes de la Aegyptiaca de Manetón conservados en Flavio Josefo y otros autores clásicos como Eusebio y Africano (Waddell, 1940); la Inscripción del Speos Artemidos de Hatshepsut (Dinastía XVIII) o la narrativa de índole literaria denominada La disputa entre Apofis y Seqenenra (Dinastía XIX, reinado de Merenptah). ${ }^{11}$ Estas dos últimas evidencias son conocidas desde el siglo XIX, mientras que Manetón fue la autoridad al respecto desde tiempos previos. El corpus referido a Kamose, último rey de la Dinastía XVII tebana que comenzó el accionar bélico sistemático contra los hicsos, presenta sus propias vicisitudes y se fue incorporando a la discusión en la medida que se fueron hallando y traduciendo sus estelas halladas en el templo de Karnak, entre inicios y mediados del siglo XX. ${ }^{12}$ Como se puede deducir fácilmente, Manetón fue el autor que determinó durante mucho tiempo la lectura sobre los hicsos y el SPI en general. Sus apreciaciones hablan de un Egipto anómico invadido por hombres "de una raza oscura" provenientes del Este a los que no se les ofreció resistencia alguna, y ésta fue la lectura habitual durante bastante tiempo, dado que la imagen negativa de los hicsos que presentan los documentos egipcios hallados con posterioridad no contradicen lo sostenido por Manetón. Sin embargo, y a diferencia de las lecturas que se realizan sobre el PPI a partir de la trasposición automática del contenido de las narrativas posteriores, para el SPI la localización de Avaris en 1966 significó un quiebre relevante para esas interpretaciones, que se fue consolidando $-y$ complejizando- a lo largo del tiempo. ${ }^{13}$

La problemática del TPI (ca. 1100-650 a.C.) se define sustancialmente por el control extranjero de Egipto, bajo el rótulo bastante extendido de "anarquía líbica”. Libios -y luego nubios también- avanzaron sobre el territorio y las estructuras del Estado egipcio a través de diversas prácticas, y le dieron su impronta particular. Las denominadas estelas de donación, a las que luego haremos referencia, abonan la impresión de un lapso "anárquico". A ello se suma que no hay registro alguno en las listas regias locales de los reyes que gobernaron durante este lapso; la recopilación de la información corre por cuenta de una de las fuentes tardías ya mencionadas: Manetón.

Debido en parte a la falta de información local sobre los reinados, el estudio histórico del TPI se basó, tradicionalmente y además de Manetón, en las 
menciones realizadas en la Biblia a algunos reyes que pueden ubicarse en el $\mathrm{TPI},{ }^{14}$ o bien dándole suma relevancia a la referencia al matrimonio de Salomón con una princesa egipcia hecha en el Libro de Reyes (1 Reyes 11:19-20). Sin embargo, no sólo la datación de la puesta por escrito de los contenidos del texto bíblico es un tema ampliamente discutido (cf. Finkelstein y Silberman, 2003 [2001]; Lemche, 1993: 163-193; Pfoh, 2009: 121-160) sino que la información que brinda acerca de los sucesos en Egipto es casi nula, siendo útil para cuestiones de cronología relativa. Otro corpus documental utilizado para reconstruir la dinámica del TPI -aunque de modo parcial- son los registros asirios que refieren a los enfrentamientos con los egipcios en los territorios levantinos, aunque estos documentos son escuetos en lo que refiere a la situación en Egipto dado que se limitan a aquel escenario territorial (van De Mieroop, 2011: $\$ 11.1$ "The Concordat").

Ahora bien, en términos generales y volviendo al punto de partida de este apartado, ¿se debería descartar de plano la información que la documentación más tardía -o la proveniente de otros contextos socio-históricos- puede brindar sobre una determinada situación histórica? En modo alguno. Sin embargo, consideramos que debe ser contextualizada -dado que su valor puede referir a cuestiones contemporáneas a tal documentación más que a hechos pasados, y que tales cualidades están ligadas a la memoria social (o cultural) que apela a esas situaciones pasadas por su vinculación con el presente que las evoca- con lo cual sería prudente que fueran consideradas como evidencia secundaria, priorizando las evidencias contemporáneas a la situación que se pretende analizar.

\section{El Primer Período Intermedio (ca. 2200-2000 a.C.)}

La influencia que los documentos posteriores ejercieron sobre las caracterizaciones de los Períodos Intermedios como lapsos anárquicos, revolucionarios, de guerra civil u "oscuros", derivó en la búsqueda de una causa base por la cual explicar la dinámica turbulenta y caótica de tales procesos. Así, para el PPI, se encontró en un factor de índole externa -la "cuestión climática" y la consecuente movilización de extranjeros en la frontera nororiental de Egipto- una razón que gozó de recurrente presencia en los estudios académicos referentes al tema. Por cierto, es sabido que el régimen del Nilo no es regular y que recién pudo ser controlado con la creación de la represa de Asuán en el siglo XX de nuestra era, y que ya hubo intentos en época dinástica de tratar de controlarlo por medio de la creación de diques o barreras a la altura de Nubia. ${ }^{15}$ Las evidencias textuales y materiales muestran la relevancia que el Estado le daba al conocimiento de la altura de las crecidas del Nilo, detectadas a través de los llamados "nilómetros". ${ }^{16}$ Ahora bien, la hipótesis relativa a una catástrofe climática de amplio alcance y coincidente con el reinado del último rey de la Dinastía VI como base para explicar la problemática del PPI debería ser puesta entre paréntesis hasta tanto no se cuente con datos más confiables ${ }^{17}$ (por ejemplo, determinar si el proceso de aridización que tuvo lugar en el III milenio a.C. coincide o no en términos absolutos con el reinado de Pepi II) admitiendo que, en líneas generales, estos fenómenos y sus consecuencias, como las migraciones, podrían haber actuado como catalizadores del proceso, pero en modo alguno como
14. Como Shoshenq I (Sisac, mencionado en los libros de Reyes y Crónicas); Osorkon I (So, en Reyes); Taharqa (Tirhaca, en Reyes); y dos pertenecientes a la Dinastía XXVI: Necao (Necho, en Reyes, Crónicas y Jeremías) y Wahibra (Hofra, en Jeremías).

15. Una serie de indicios permiten especular sobre los intentos de control de las crecidas del Nilo en la Baja Nubia durante el reinado de Amenemhat III (Dinastía XII), Vercoutter, 1998: 41. 16. Como lo indica la Piedra de Palermo al señalar la altura del río. Sobre este punto cf. Hsu, 2010: 82. 17. Actualmente se está llevando a cabo un proyecto donde se trata de establecer esa vinculación y la posibilidad de determinar cuán grave fue la baja en el nivel de la inundación del Nilo. Cf. Dee, 2017: 327-329. 
18. En inglés “event 4.2 ka B.P.”

19. Se estableció la contemporaneidad del Bronce Temprano III con la tardía Dinastía I (Nagada IIIC2) hasta mediados/fines de la Dinastía IV (reinados de Keops o Shepseskaf), lo que ubicaría la transición entre el Bronce Antiguo y el Medio - lo que se denomina el Bronce Antiguo Intermedio -entre fines de la Dinastía IV y fines del PPI (Adams, 2017: 496). disparadores del mismo. Actualmente se están revisando las hipótesis relativas al llamado "evento $4200 \mathrm{AP}$ "18 (o 2200 a.C.) en referencia al problema climático vinculado a la sequía que afectó al Cercano Oriente Antiguo en ese momento. Precisamente, una de las variables que se remarcan hoy día en referencia a su alcance es su impacto relativo y heterogéneo. Los estudios más recientes sobre el sur del Levante revelan un ajuste de la cronología relativa ${ }^{19}$ y permiten plantear nuevas hipótesis en torno a la "desaparición" de las grandes urbanizaciones en la región, que tendría que ver con una adecuación de las élites locales a nuevas tendencias productivas donde la arquitectura monumental se volvió prescindible (Schloen, 2017: 69). Todas estas nuevas perspectivas deben ser tomadas en cuenta al evaluar la incidencia de la situación en el Levante sobre la dinámica del PPI.

Algo semejante sucede con otro de los aspectos habitualmente subrayados cuando se remite al "colapso" que representó el PPI, pero de índole interna. Nos referimos al tema de las hambrunas que, si bien aparecen mencionadas en los documentos del PPI provenientes del Alto Egipto, no son privativas del mismo, sino que en ese momento el motivo del hambre se transformó en un tema recurrente sostenido por las nuevas élites locales como medio de legitimación, y desapareció en los inicios del Reino Medio con la reunificación del Estado (Schneider, 2017: 314).

Ahora bien, como consecuencia de asumir la existencia de una brutal crisis climática y de hambrunas de carácter excepcional, y por ende de una baja en la producción de bienes de subsistencia, la historiografía le atribuyó una importancia relevante a los "decretos de inmunidad" que eximían del pago de impuestos, en particular, al templo de Min (Coptos B, C, y D) que fueron promulgados a partir de los reinados de Pepi I y Pepi II Neferkara hasta la Dinastía VIII. Sin embargo, la emisión de decretos, entre ellos los de inmunidad, era una potestad que tenía la realeza y que utilizaba habitualmente, no estando limitada a fines de la Dinastía VI, el momento "previo" al PPI (Daneri de Rodrigo, 1992: 119).

Otro elemento que puede sumarse a este panorama de explicaciones habituales es la prolongada duración del reinado de Pepi II. Sin embargo, no suele hacerse una consideración semejante con otro reinado igualmente largo, como el de Ramsés II. Ambos gobernaron más de sesenta años, pero las lecturas sobre ellos son radicalmente opuestas, en tanto se apoyan en las situaciones históricas posteriores para definirlas (Schneider, 2017: 312); con lo cual, la duración de un reinado per se no debería ser considerada causal directa de una crisis.

¿Qué es entonces lo que sí puede verificarse para el PPI? Siempre teniendo en cuenta que la fase final del PPI está mejor documentada que la primera, los hechos comprobables que muestran las diferencias entre el Reino Antiguo y el PPI pueden resumirse en torno a la independencia que muestran las elites del Alto Egipto -legitimadas ahora por los dioses locales en desmedro de la autoridad del rey, como lo demuestra la autobiografía de Ankhtifi de Móalla- y el cambio significativo en la cultura material de esa región, que incluso muestra diferentes trayectorias de desarrollo cultural (Seidlmayer, 2003 [2000]: 131-132). 
Otros factores evidencian que ciertos cambios en la organización territorial del Estado tuvieron lugar a partir de la Dinastía VI, los que J. C. Moreno García (2013a: 124-125) resume y apunta de modo convincente. Señala que una de esas novedades refiere a la designación de "gobernadores provinciales" ("gran jefe del nomo", "nomarca") en el Alto Egipto, a la vez que los antiguos centros agrícolas de la corona en los nomos fueron desapareciendo para dejar paso a los denominados “dominios" - ḥw(w)t (cf. también Seildmayer, 2003 [2000]: 111). Asimismo, sostiene que los nomos del Bajo Egipto estaban controlados desde Menfis, mientras que no sucedía lo mismo con los del Alto Egipto, donde tampoco la situación era completamente homogénea. En ciertos lugares, como Coptos o El-Hawawish, no hay evidencia de los responsables de los "dominios" - sólo uno se conoce en el-Kab- mientras que, a la vez, existían dinastías de sacerdotes que por seis u ocho generaciones tuvieron bajo su control los templos en esas tres localidades. Como vemos, las variaciones locales apuntan a una mayor independencia de ciertos nomos del Alto Egipto del gobierno central, cuyos líderes comenzaron paulatinamente a denominarse "hijos" del dios local, a datar sus inscripciones por sus propios años de gobierno y a erigirse complejos funerarios relevantes.

Es factible que las declaraciones de estatus social y vínculos personales que refieren estos líderes locales del Alto Egipto, apunten a fortalecer la hipótesis -primero presentada por J. Assmann en 1996 (2002: 96 y ss) y más tarde por D. Franke (2006) - de la existencia de una articulación social ligada al patronazgo en el área tebana durante el PPI. ${ }^{20}$ En la misma línea, Moreno García (2013b: 1042) sostiene que el patronazgo, una práctica sociopolítica subyacente a lo largo de toda la época dinástica, suele ser mejor visualizada en lapsos disruptivos. Definida como un vínculo diádico (Eisendstadt y Roniger, 1980: 49-50), es decir, personal entre dos individuos -que pueden o no estar ligados por lazos de sangre-, y que toma la forma de redes de relaciones organizadas jerárquicamente, suele ser de carácter informal (es decir, no suele estar regulada por normativas legales), y se caracteriza por una reciprocidad asimétrica donde el patrón entrega bienes y protección al cliente a cambio de fidelidad y servicios (Abercrombie y Hill, 1976: 422). Ahora bien, ¿ cómo se la puede rastrear en los documentos? De hecho, se evidencia el uso de un lenguaje asociado al parentesco y a la "casa patrimonial". De este modo, "padre", "hijo", "hermano", "servidor", "seguidor", "señor" e incluso "amigo", suelen ser las palabras-clave que permiten inferir la posible existencia de tal práctica. Además, el carácter constitutivo de este tipo de vínculos permite una circulación vertical del poder, estableciendo lazos solidarios entre distintos estamentos sociales (Moreno García, 2013b: 1046).

El ejemplo que mejor ilustra esta condición -aunque no el único- es el del ya mencionado Ankhtifi, el poderoso "gran jefe del nomo" III del Alto Egipto (Hieracómpolis), quien en los textos inscriptos en su tumba, ubicada en la frontera norte del nomo, en Mo'alla, hace alardes claros de su independencia, su fuerza de carácter, su condición de líder y sus emprendimientos, y remite su legitimidad al mismo dios Horus, y no a un rey en particular. Además, como señala Assmann, en sus inscripciones aparece contundentemente el leitmotif de la "solidaridad vertical" donde se lo visualiza como un proveedor benevolente:
20. Sobre la lógica del patronazgo, pero también la estatal y la parental en las inscripciones de Ankhtifi, cf. Campagno, 2011. 
“Dí pan al hambriento y vestimentas al desnudo, ungí a los que no estaban ungidos, calcé al descalzo, le di una esposa a quien no tenía esposa. (...) Toda esta tierra se ha transformado en una langosta en el viento. Unos viajan río abajo, otros río arriba, pero nunca permití que uno lleno de pena de este nomo terminara en otro nomo. Yo soy [un héroe sin par]." (Assmann, 2002: 101. La traducción me pertenece).

Por cierto, estas características de independencia, autodeterminación y legitimación ejercidas a través de la ejecución de buenas acciones en sus distritos, no son exclusivas de los más altos funcionarios como Ankhtifi, cuya titulatura recoge doce títulos, entre honoríficos, religiosos, militares y aquellos que tenían que ver directamente con la administración del nomo (Vandier, 1950: 19-20). Iti, un tesorero del rey originario de Imitru - una localidad cercana a Gebelein- indica en las inscripciones de su tumba, además de referirse a sus cualidades al frente de su localidad y a acciones semejantes a las referidas por Ankhtifi, que "(si) yo servía a un gran señor, o (si) servía a un pequeño señor, no hubo quejas (lit: nada provino de ello)" (Lichtheim, 1988: 31-32, la traducción me pertenece). Es interesante observar que el verbo que se utiliza es $\breve{m} m s$, que habitualmente se traduce como "seguir", "acompañar", o "servir", en este caso, a un "señor".

En el mismo sentido, los Textos de los Sarcófagos datados en el PPI, revelan una serie de conjuros que están dirigidos a "reunir la familia de un hombre en el reino de los muertos". Los textos mencionan no sólo a los familiares más cercanos sino también a "servidores, seguidores y amigos" enfatizando la importancia de las relaciones sociales interpersonales en ese momento en el Alto Egipto (Seildmayer, 2003 [2000]: 115). Es en la misma línea que consideramos otros elementos que aparecen en las evidencias, como el énfasis puesto en la superación personal debida al esfuerzo propio y no al favor regio, corporizado en la figura del $n \underline{d} s$ (Moreno García, 1997: 34). La palabra $n \underline{d} s$ posee varias acepciones, frecuentemente de índole negativa al estar clasificada con el signo G37, el gorrión. A. David realizó un exhaustivo trabajo sobre el signo en cuestión, concluyendo que durante el PPI se lo asocia a los conceptos de "inferioridad" por tamaño, edad, función y estatus (la inferioridad moral estaría representada por el término bjn también clasificado con G37) y se lo podría asociar fundamentalmente con las ideas de humildad, modestia y simplicidad (David, 2000: 43-44). Sin embargo, hay dos categorías que se despegan de los simples $n \underline{d} s w$ y adquieren valores diferentes: se trata del $n \underline{d} s k n$ y el $n \underline{d} s j k \underline{j}$. El primero refiere al vigor que da la juventud o el valor, mientras que el segundo hace referencia a un sujeto que se expresa "para afirmar su excelencia, su eficacia, bajo una cubierta de falsa modestia (...), o que se refiere a sus modestos orígenes para señalar que se elevó socialmente" (David, 2000: 47, la traducción me pertenece). Así, estos individuos corporizaban de alguna manera el logro material a través del esfuerzo propio al no depender de los mecanismos del Estado para obtener sus bienes o disponer de ellos, vale decir, poseían la capacidad de actuar por ellos mismos (Moreno García, 1997: 38-39). Sin embargo, aunque libres, seguían sujetos a las estructuras de poder existentes en el área, con lo cual, el "esfuerzo personal" al que refieren también podría ser interpretado como la capacidad de obtener bienes a través de las redes sociales de interacción a las que nos referimos con anterioridad. 
En síntesis, el PPI significó un lapso disruptivo en tanto las dinastías de reyes, localizadas en Heracleópolis, no ejercieron control sobre todo el territorio egipcio. Los jefes locales de los núcleos del Alto Egipto se independizaron y es muy factible que los lazos de parentesco y de patronazgo hayan resultado la modalidad que las diversas élites adquirieron para vincularse y legitimarse, hasta tanto uno de tantos "patrones" se erigió en "rey" -proceso donde la violencia bélica tuvo lugar, en tanto compatible con la dinámica que este tipo de vínculos habilita- primero con una autoridad ligada al Alto Egipto (el rey Mentuhotep Nebhepetre de la Dinastía XI -a quien se le atribuye la reunificación- no abandonó Tebas y erigió su templo funerario en Deir el-Bahari) y luego desde el Egipto totalmente unificado (la Dinastía XII), con centro en una nueva localidad (Itj-tawy, El-Fayum). Para este momento, una nueva línea dinástica estaba establecida y no sin dificultades -recordemos la muerte violenta de Amenemhat I- logró poner las bases para un prolongado lapso de unificación estatal.

\section{El Segundo Período Intermedio (ca. 1800-1530 a.C.) $)^{21}$}

Así como la crisis climática sirvió como base de sustentación para definir las cualidades intrínsecas del PPI, las "invasiones extranjeras" lo fueron -durante largo tiempo- para el SPI. Aquí, las expresiones conservadas por una autoridad como Manetón tuvieron un peso significativo en las interpretaciones historiográficas, ya que incluso se vieron corroboradas por la información provista por evidencias egipcias como las ya mencionadas Inscripción del Speos Artemidos (Hatshepsut, Dinastía XVII) y La Disputa entre Apofis y Seqenenra (Pap. Sallier I, EA 10185; Merenptah, Dinastía XIX) -conocidas desde el siglo XIX- con su mirada negativa sobre los hicsos. También se trató de dar un marco explicativo basado en factores climáticos, buscando probar una serie de altas crecidas del Nilo que pudieron haber afectado al Estado egipcio de modo sistémico. Sin embargo, hoy en día - al igual que para el PPIse está favoreciendo una explicación donde convergen múltiples factores, de índole interna y externa.

A diferencia del PPI, el SPI presenta variables que estaban ausentes en el período disruptivo anterior. De hecho, se verifica la existencia de la primera dinastía con una fuerte impronta cultural extranjera -particularmente con caracteres culturales del norte del Levante- que reinó en Egipto: me refiero a los hicsos, que comprendían la Dinastía XV según el papiro de Turín, donde aparecen mencionados (Ryholt, 1997: 118). ${ }^{22}$

Asimismo, el avance de los nubios sobre las fortalezas de la Baja Nubia erigidas por los egipcios durante el Reino Medio, también produjo un impacto relevante en diversas esferas de la sociedad egipcia. Las singularidades que marcan este período se van dilucidando en la medida en que la evidencia aumenta: así, las excavaciones que desde hace más de 50 años se vienen realizando en Tell elDab'a/Avaris, la antigua capital de los hicsos; los trabajos que se llevan a cabo en los oasis de Kharga y Dakhla; y los recientes descubrimientos efectuados en las necrópolis de Abidos permiten reconstruir de modo algo más preciso
21. Sigo la propuesta de K. Ryholt (1997: 1) de establecer el inicio de este proceso disruptivo a fines de la dinastía XII/inicios de la XIII.

22. Para una discusión sobre el probable origen de los hicsos, cf. Bietak, 2010. 
-aunque no exento de dificultades- la dinámica de un proceso poco conocido, pero indudablemente mucho más complejo que lo considerado hasta ahora (Flammini, 2016).

Es factible que a fines de la Dinastía XII (ca. 1800 a.C.) haya tenido lugar una crisis sucesoria en la línea gobernante (Wegner y Cahail, 2014: 22-23). Tal crisis, transformada en crisis de legitimidad -como lo prueba el uso del nombre del progenitor acompañando el propio por parte de los reyes de la Dinastía XIII (Ryholt, 1997: 208)- pudo haber motorizado un proceso de disputas por el acceso al trono entre distintas líneas que podían pretenderlo. Esta es una hipótesis que se basa en la gran cantidad de reyes que componen esta dinastía -más de 57- y que llevó a S. Quirke (1991: 137-139) a sostener que la realeza "circulaba" entre dirigentes locales, y a K. Khótay (2013: 484) a mencionar la "cooperación" como práctica base gestada entre ciertos grupos que competían por el poder. Ahora bien, en modo paralelo a estas circunstancias de índole política, el dominio $(h w t)$ establecido con gran probabilidad por la corona a fines de la Dinastía XII en Tell el-Daba/Avaris, y de fuerte impronta cultural ligada al norte del Levante, fue adquiriendo paulatinamente mayor independencia, centrando sus actividades fundamentalmente en el intercambio con esa región de Asia occidental.

Varios temas relativos al SPI permanecen abiertos. Uno tiene que ver con las cronologías tradicionales (relativa y absoluta), que fueron puestas en duda por los recientes hallazgos hechos en Tell el Dab'a/Avaris (Área R/III) y Edfu, que se componen por improntas de sello. Tales evidencias revelan que el rey hicso Khayan, considerado habitualmente como el predecesor de Apofis, y por lo tanto uno de los últimos reyes de los hicsos, debería ser reubicado a inicios de la Dinastía XV y no a fines de ella (Moeller y Marouard, 2011, sin embargo a este respecto, cf. Schneider, 2018).

Otro tema de discusión tiene que ver con el supuesto "abandono" de Itj-tawy por parte de los reyes de la Dinastía XIII y su "huida" a Tebas ca. 1700 a.C. El argumento que sostiene esta hipótesis se basa en la ausencia de vestigios de esta dinastía en el norte luego del reinado de Merneferra Aya, aunque también hay fuertes argumentos que tienden a cuestionar esta hipótesis, puesto que tampoco hay hallazgos certeros en el sur. Con lo cual, también es factible que esos gobernantes hayan permanecido en el norte pero subordinados a los hicsos. Precisamente, otro punto que tiene que ver con estas cuestiones es tratar de comprender el modo en que los hicsos extendieron su control sobre parte del territorio. Aun cuando no produjeron narrativas, ciertas evidencias permiten sostener que establecieron prácticas de subordinación personales con los jefes locales en lugar de emprender una dominación territorial extensa. La Segunda Estela de Kamose permite inferir esta práctica: el líder hicso Apofis pretendía controlar el Alto Egipto subordinando políticamente al gobernante tebano. En esta misma línea, el hecho de que Apofis en el texto llamase al gobernante de Kush "mi hijo", refleja el modo en que los hicsos desplegaban sus vínculos inter-elite, probablemente a través de intentos de subordinación que pueden vincularse con el ejercicio del patronazgo. El título "hijo de rey", ampliamente atestiguado en escarabajos, también probablemente refleje esta clase de vínculo, así como la distribución de objetos vinculados al prestigio, como armas en el 
Delta oriental y el sur del Levante. Asimismo, se observa una fuerte tendencia por parte de estos gobernantes a conformar una identidad de elite diferencial, donde si bien se observa la adopción de ciertos rasgos de la cultura local, otros son propios y permiten sostener que existió cierta intencionalidad en diferenciarse de la realeza egipcia y no en asemejarse a ella (Flammini, 2013).

Si bien los hechos de índole política reconstruidos a través de la documentación escrita no se correlacionan directamente con las secuencias de los vestigios arqueológicos, la evidencia material que proviene de los cementerios datados en el SPI revela que el colapso del Estado unificado dejó a la vista variaciones culturales locales, expuestas por la gravitación de los sucesos políticos.

De hecho, mientras la Dinastía XV estaba bien establecida en el Delta oriental, y Avaris se convertía en una imponente ciudad-puerto, la situación en el Alto Egipto siguió su propio camino hacia una mayor fragmentación política, que parecería haberse incrementado ca. 1650 a.C. Varios centros independientes emergieron en el sur y entraron en competencia entre sí. Esta situación es novedosa en tanto quiebra la idea de una situación homogénea durante todo el SPI, encarnada en las tres entidades sociopolíticas representadas por los hicsos, los tebanos y los nubios, que de hecho se corporizará recién a finales del proceso. ${ }^{23}$

Durante la última década se realizaron nuevos hallazgos en sitios localizados en los principales oasis ubicados al oeste de Tebas (Dakhla y Kharga) y en las rutas que los conectaban con la zona tebana, que actuaban como puntos de conexión en un área atravesada por una extensa red de rutas que estuvieron en uso mucho tiempo antes de la fragmentación del Estado. Ambos sitios estaban dedicados a la producción de alimentos, en particular, de pan. En un contexto de fragmentación política, estos núcleos actuaban de modo independiente, quizás como intermediarios en los contactos establecidos entre Avaris y Kerma cuando la ruta de los oasis se vio favorecida en desmedro de la del Nilo. Tal situación revela el aislamiento de Tebas, lo que implicó que ciertas variables locales cobraran fuerza. Así, los templos -en particular el de Amón- fueron adquiriendo cada vez más un rol central, los más altos cargos del funcionariado se volvieron hereditarios, y se constituyeron poderosas familias locales (Moreno García, 2009: 285-291). A su vez, la cultura material revela un empobrecimiento de los recursos: los ataúdes eran hechos de madera de sicomoro, de origen local, en lugar de la madera de cedro importada del Levante; la cerámica adquirió formas locales y la materia prima también era local. Tal localismo se evidencia también en variables de otro orden: el uso colectivo de ciertas áreas de culto puede ser interpretado como una necesidad de afianzar la identidad de pertenencia, distinguiendo entre los que pertenecían al grupo social y los que no; y la aparición de una colección local de conjuros relacionados con la vida de ultratumba (el Libro de los Muertos), puede entenderse como producto del aislamiento de Menfis, sus escribas y bibliotecas, que se encontraban bajo el control de los hicsos.

Otra hipótesis de trabajo refiere a la manera en que los gobernantes tebanos reconstruyeron su poder, expandiéndolo, para finalmente vencer a los hicsos. Por cierto, la reunificación y posterior expansión del Estado se trató de un
23. La posible existencia de una dinastía independiente en Abidos fue propuesta hace tiempo, primero por D. Franke y luego por K. Ryholt, basándose en la información provista por el Papiro de Turín, que registra un grupo de gobernantes luego de la sumatoria de la Dinastía XVI. Pero fue el reciente hallazgo de la tumba de un rey llamado Woseribra Senebkay en Abidos Sur, lo que dio un nuevo ímpetu a tal hipótesis. Tal dinastía fue probablemente contemporánea de la Dinastía XVI tebana (ca. 1650-16oo a.C.), cf. Wegner, 2014; Flammini, 2016. 
24. Sobre esta cuestión y las fuentes de Manetón, cf. Adams, 2011: 25-27. largo proceso que se inició con la Dinastía XVII y continuó bien adentrada la Dinastía XVIII. Es factible que la consolidación de la supremacía tebana se basara en diferentes hechos, principalmente en: a) un fuerte refuerzo de los lazos sociales locales, b) la recuperación de la fortaleza de Buhen, que habría permitido el acceso a un recurso relevante como es el oro; c) la expansión hacia el oeste (la ruta de Girga y los oasis) y d) la estrecha relación con ciertos grupos sociales nubios (los Pan-Grave/Medjay y el Grupo C), que habitualmente eran incorporados como mercenarios a los ejércitos egipcios (para la relación con el Grupo C, cf. Hafsaas-Tsakos, 2008: 394-395).

En síntesis, las evidencias contemporáneas muestran un proceso de fragmentación socio-política mayor de lo habitualmente considerado, en particular en el Alto Egipto; la emergencia de una línea dinástica vinculada al extranjero; la emergencia de los rasgos culturales locales, tanto en la cultura material como en las prácticas sociales y en la formación de identidades de élite; la activación de rutas alternativas de intercambio y prácticas de subordinación que posiblemente puedan asociarse al parentesco y al patronazgo.

\section{El Tercer Período Intermedio (ca. 1100-650 a.C.)}

El TPI se corresponde con los reinados de las Dinastías XXI a XXV, aunque hay que hacer la salvedad de que los nombres de los gobernantes que las conformaban no aparecen registrados en ninguna lista de reyes, con lo cual su ordenamiento se realizó en base a los escritos de Manetón, ${ }^{24}$ cotejando esos datos con las evidencias que se hallaron en Egipto y con la información suministrada por otros documentos provenientes del exterior (Taylor, 2003 [2000]: 324-325). Por cierto, la cantidad proporcional de evidencia no es homogénea a lo largo del territorio egipcio, siendo más abundante la proveniente del área tebana en comparación con la que se halló en el Delta, significativamente menor.

Mencionadas estas limitaciones documentales, cabe señalar que la fragmentación política y la emergencia de nuevos actores hicieron su aparición en el nuevo proceso disruptivo cuando, luego del avance de los "pueblos del mar" y la crisis del 1200 a.C., Egipto se vio expuesto a la instauración de prácticas sociopolíticas diversas, como veremos más adelante.

Varios son los temas sobre los cuales ronda el interés científico en relación con esta situación histórica, aunque algunos en particular suelen recibir un alto grado de atención como, por ejemplo, el grado de aculturación de los libios en Egipto o las dinámicas que adquirió la fragmentación política. Por cierto, los libios -actores cuasi excluyentes del TPI, aunque recordemos que el período finaliza con la llegada al trono de una dinastía de origen nubio, la XXV- habían comenzado ya su entrada en Egipto desde fines del Reino Nuevo, y se ubicaron principalmente en un área localizada entre Menfis, Heracleópolis y los oasis del desierto occidental. De hecho, es en el Delta occidental donde se verifica la mayor concentración de libios. Muchos de ellos habían servido en los ejércitos egipcios y habían recibido tierras a 
cambio de sus servicios, con lo cual los jefes de estos grupos de mercenarios lograron ubicarse en ciudades de relevancia como las ya mencionadas, a las que logaron controlar.

Los grupos libios instalados en el norte eran los Meshwesh (o Ma), que se ubicaron principalmente en el centro y al este del Delta (en Mendes, Bubastis, y Tanis); los Libu, que ingresaron luego que los Meshwesh, y conformaron la dinastía residente en Sais, y los Mahasun que se ubicaron más al sur. En el Alto Egipto, Tebas, asociada a la tradición egipcia propiamente dicha, fue capaz de mantener su estatus central durante todo el TPI (Taylor, 2003 [2000]: 338-339).

Si bien es factible que algún grado de aculturación entre los libios y los elementos locales haya tenido lugar, los libios conservaron varios marcadores étnicos: los nombres, los títulos relacionados con la jefatura, los tocados adornados con una pluma, y el establecimiento de largas genealogías indicativas de la importancia del parentesco en estas comunidades (Leahy, 1985; O'Connor, 1990; Ritner, 2009). Sin embargo, hay quienes se preguntan en qué medida la pertenencia a alguno de los distintos grupos étnicos libios era reconocida por la sociedad egipcia, teniendo en cuenta que los libios ya hacía varias generaciones que estaban asentados en Egipto, y proponen una lectura alternativa, argumentando que los gobernantes libios podrían utilizar tales marcadores étnicos para realizar diferenciaciones hacia el interior del grupo gobernante (Riggs y Baines, 2012: 6-7). Además, hay quienes sostienen que para los libios el título de "rey" no tenía las mismas connotaciones que para un egipcio y que incluso la idea de la existencia de un único rey tampoco estaba arraigada en su concepción del poder (Broekman, 2010) con lo cual, el "rey" llegó a ser un primus inter pares, ubicado muy lejos de la concepción egipcia tradicional de esta figura.

Ahora bien, ¿cómo se fueron entretejiendo estas situaciones en el devenir histórico? Si bien la Dinastía XXI mantuvo la unidad política, el control territorial estuvo manifiestamente dividido entre el norte y el sur. Esta dinastía residía en el norte, en Tanis, mientras que en Tebas el poder era ejercido por el "gran sacerdote de Amón”. Sin embargo, los gobernantes de Tanis y los grandes sacerdotes de Amón residentes en Tebas estaban emparentados, con lo cual más allá de la existencia de una frontera territorial entre el norte y el sur que estaba fijada en el-Hibeh ( $t 3 y w d 3 y t$, ubicada en la entrada a el-Fayum y prácticamente convertida en una fortaleza en ese momento), los vínculos entre el norte y el sur eran amigables. Como bien resume las características de este lapso van de Mieroop (2011: 11.1 § The Concordat): "En la dinastía XXI la casa real norteña gobernaba nominalmente todo el país, pero en la realidad, permitió que otra rama de la familia gobernara el sur en base a su oficio religioso". ${ }^{25}$ Es factible que estos gobernantes hayan sido de origen libio y gobernaran con nombres egipcios, dados los vínculos que se pudieron establecer entre esta dinastía y la sucesora, la XXII, abiertamente "líbica" (Ritner, 2009: 2).

Como ya señalé, durante el TPI emergieron diversas prácticas, algunas novedosas. Una de ellas es la instauración de una teocracia durante la Dinastía XXI: el verdadero "rey de Egipto" era el dios Amón. La conocida hipertrofia del templo de Amón en Karnak, iniciada probablemente con las prácticas establecidas
25. La traducción me pertenece. Para ilustrar estos vínculos mencionaremos que Psusennes I (tercer rey de la Dinastía XXI, gobernó desde Tanis), era hijo del comandante tebano Pinedjem I y hermano del gran sacerdote de Amón Menkheperra. 
entre los gobernantes de Tebas y los sacerdotes locales en el SPI, y consolidada durante el Reino Nuevo, ahora continuaba en expansión con la adquisición de tierras y la consecuente acumulación de poder. Allí, el dios era consultado para que validara las órdenes del rey a través de oráculos, como lo ejemplifica un caso de donación de tierras (Cairo JE 45327; Menu, 1998: 141-143). La estela Louvre C256, conocida también como la Estela del Destierro (o de Maunier, datada posiblemente en el año 25 del reinado de Smendes, primer rey de la Dinastía XXI), evidencia la consolidación del poder del recién instaurado gran sacerdote de Amón Menkheperra a través de esa práctica. En ella, se relata que el gran sacerdote fue emplazado por la divinidad a desterrar a los integrantes de una facción enemiga vencida al oasis de Kharga, después que organizaran una revuelta en los dominios del dios. La facción desterrada luego fue perdonada por la piedad del dios y de Menkheperra, y es en esa circunstancia que el gran sacerdote recita un himno donde exalta la autoridad inigualable de la deidad y su disposición al perdón, cualidades que, por carácter transitivo, él también poseía (cf. Ritner, 2009: 124-129 y bibliografía citada allí). El clero de Amón durante este lapso obtuvo tal poder que llegó a incorporar la iconografía real en su dogma teológico (Van Walsem, 1992: 642-645). De este modo, en un Himno a Amón conservado en un papiro hallado en Deir el Bahari, el nombre del dios está escrito dentro de una cartela y es mencionado como el supremo entre todos los dioses, el manantial de la creación, y el verdadero rey de Egipto (Taylor, 2003 [2000]: 327).

Ahora bien, luego de este lapso donde la unidad se mantuvo en un escenario político que podríamos denominar "bifronte", accedió al trono en el Delta un hijo de un tal "Sheshonq, jefe de los Meshwesh", conocido como Osorkon el Viejo. Este individuo, ya de indudable origen libio, se transformó en el quinto rey de la Dinastía XXI. Por cierto, la sucesión entre las Dinastías XXI y XXII evidencia la existencia de vínculos de parentesco entre sus integrantes: Osorkon el Viejo fue sucedido por Siamun y luego por el "gran sacerdote de Amón” Psusennes (II). Este último fue sucedido por Sheshonq I (originario de Bubastis, quien dio inicio a la Dinastía XXII y era sobrino de Osorkon el Viejo), quien a su vez lo fue por Osorkon I, a la sazón hijo de Sheshonq I y de Maatkara, hija de Psusennes II.

Los reinados sucesivos vieron crecer el poderío del funcionariado en el Alto Egipto en tanto los cargos se volvieron hereditarios, a pesar de los intentos de los reyes libios de mantener el control a través de la colocación de sus descendientes directos en el sensible cargo de "gran sacerdote de Amón": por ejemplo, Sheshonq I (primer rey de la Dinastía XXII) nombró en ese cargo a su hijo Iuput. Por cierto, la fragmentación política característica de este período continuó su derrotero. Así, durante el reinado de Sheshonq III, los jefes locales, principalmente del Delta, se declararon a sí mismos "reyes", con lo cual, para 730 a.C., al momento de la conquista del territorio por parte del nubio Piankhy (o Piye, ca. 747-716 a.C.), coexistían dos reyes en el Delta (en Bubastis y Leontópolis), dos en el Alto Egipto (en Hermópolis y Heracleópolis) - con lo cual la Dinastía XXIII fue contemporánea con los reinados finales de la XXII, la XXIV y los primeros reinados de la XXV- y un gran número de "grandes jefes" y "jefes de los Ma y de los Libu" (cf. Grimal, 1981: 1-3; Taylor, 2003 [2000]: 331). 
La denominación más habitual para ilustrar este lapso es la de "anarquía líbica”, marcando la fragmentación política por un lado y la etnia de las dinastías gobernantes por el otro. Sin embargo, un análisis más pormenorizado de la evidencia permite sostener que tal "anarquía" tuvo que ver con la inserción de otros modos de articulación social -los lazos de parentesco y probablemente de patronazgo- en instituciones de orden estatal, que adquirieron la dominancia en las prácticas sociales y políticas. Ahora bien, precisamente por el reconocimiento de estas cuestiones, R. Ritner (2009: 2-3) señala con acierto que el TPI podría ser denominado, en lugar de "anarquía líbica", como "Libia en Egipto".

La preeminencia de los jefes libios en posiciones de relevancia retroalimentaba la debilidad del rey -quien a su vez era quien debía garantizar el poder de los gobernantes locales- provocando tanto la independencia local como tensiones relativas al acceso y control de los recursos económicos. La tendencia a que los principales cargos en la burocracia, el sacerdocio y el ejército se volvieran hereditarios propició este fenómeno, reforzado además por los matrimonios entre clanes diversos que detentaban posiciones de poder (Taylor, 2003 [2000]: 335-337). Esta independencia de los centros regionales provocó la emergencia de dinastías colaterales, situación mucho más marcada en el Delta, donde se hallaban los jefes libios, y en menor medida en Tebas. De este modo, y a diferencia del PPI y del SPI, durante el TPI la descentralización fue institucionalizada como forma de gobierno, organizada como una "confederación de gobernantes semiautónomos, nominalmente dominados (y con frecuencia relacionados) a un señor-rey" (Taylor, 2003 [2000]: 338). Esta descentralización finalizó con una forzada reunificación política producto de la conquista del territorio por otro poder externo: el de los nubios que conformaron la Dinastía XXV.

¿Cómo se evidencia esta situación? Ritner (2009) propone una lectura antropológica al señalar que si se toma en cuenta el modelo de linajes segmentarios, los parientes colaterales de la línea regia, todos descendientes de un ancestro común, estuvieron inicialmente unificados, luego aliados y finalmente entraron en competencia; mientras que la burocracia "estatal" se vio subordinada a los lazos de parentesco que estas familias impusieron. De este modo, los cargos más prominentes de la administración eran ejercidos por los "Jefes de la tribu de los Meshwesh" habitualmente representados con tocados de plumas y nombres extranjeros (Crespo, 2011). Tal preeminencia de los lazos de parentesco en la administración tuvo sus efectos: por un lado, el habitual ascenso en los escalafones se vio influido por tal práctica; por otro, motivó que la nueva realeza ejecutara alianzas matrimoniales exógamas y desarrollara genealogías extensas al vincularse los individuos a la familia dinástica, algo que los nativos adoptaron a partir de este momento y que probablemente haya dado lugar al "sistema de castas" sacerdotal mencionado por Heródoto (Ritner, 2009: 2). Todo ello tenía su correlato territorial, dado que cada "Jefe de la tribu de los Meshwesh" ejercía su poder sobre un determinado territorio. Es muy factible además que a esta preeminencia de las redes parentales haya que adicionarle una fuerte impronta de la práctica del patronazgo. Son precisamente las estelas de donación las que evidencian la relevancia de estos vínculos sociales en esta etapa de la historia del antiguo Egipto. Este tipo de documentos registraba entregas de tierras a los templos o al personal que allí estaba destinado. Aquí traeré a colación el estudio realizado por K. Kitchen (1969-70) sobre una de ellas, la Estela 67.118 del Museo de Brooklyn, a 
26. Para un listado más actualizado de las estelas de donación existentes, cf. Meeks, 2009: 129-154.

27. Para su datación, cf. Depuydt, 1993. También Lichtheim, 1980: 66-84. modo de ejemplo. ${ }^{26}$ La estela menciona que en el año 22 de un rey Shoshenq (probablemente Shoshenq III de la Dinastía XXII) el gran jefe de los Ma de Mendes, Harnakht (A) le entrega tierras al flautista de Harpócrates (el "Horusniño") Ankh-Hor(pe)khrod. El texto, además de dar la ascendencia parental de ambos personajes, contiene llamativas fórmulas de maldición para aquellos que transgredieran lo pautado, y bendiciones para aquellos que lo respetaran. Además, Kitchen señala que el gobernante de Mendes Harnakht (A) data sus documentos por los años de reinado de un rey perteneciente a la dinastía libia más antigua residente en Tanis (Shoshenq III) y no por la línea más moderna encarnada por Pedubastis I de la Dinastía XXIII. Sin embargo, el sucesor de Harnakht (A) en Mendes, Smendes, le va a ser leal a Iuput, perteneciente a la línea que reinaba desde Leontópolis (Kitchen, 1969-70: 66).

Por cierto, cierta información relevante para este "cambio de lealtades" la provee la Estela de la Victoria del nubio Piankhy ya que allí se revela el número de gobernantes que halló en su campaña del año $20 .{ }^{27}$ En ese momento, los títulos regios eran reclamados por Tefnakht de Sais, Nimlot de Hermópolis, Peftiuawybast de Heracleópolis, Osorkon de Tanis y el mencionado Iuput de Leontópolis, más otros gobernantes locales (Adams, 2011: 22). Como puede observarse, la fragmentación extrema conllevaba una mutación paralela del alcance y relevancia del título de "rey".

De este modo, este cambio de "lealtades" observado por Kitchen por parte de los gobernantes de Mendes, que pasan de ser leales a los "reyes" de Tanis a serlo de los "reyes" de Leontópolis, podría ser considerado un indicio relevante para proponer la existencia de la práctica del patronazgo. Las fórmulas de castigo y bendición contenidas en estos textos, que aparecen a partir de la dinastía XXII (Kitchen, 1965: 66-67) también suelen observarse en otros documentos del Cercano Oriente antiguo habitualmente considerados como evidencia para consignar la existencia de este tipo de vínculos (como por ejemplo las Cartas de Mari, cf. Heimpel, 2003).

De este modo, el TPI muestra las consecuencias de la impronta extranjera libia en este caso- en las estructuras del Estado egipcio: fragmentación sociopolítica extrema; prácticas como el parentesco y posiblemente el patronazgo como dominantes del sistema y la reformulación del alcance del título de "rey".

\section{A modo de cierre}

Iniciamos este recorrido reflexionando sobre las denominaciones que tienden a igualar procesos disruptivos o colapsos del Estado unificado en el antiguo Egipto, los que a pesar de poseer denominadores comunes resultan lo suficientemente heterogéneos como para distinguir las formas específicas que ciertos fenómenos compartidos tomaron en cada uno de ellos. De hecho, tales denominadores comunes suelen reducirse a unos pocos: pérdida de la centralización y consecuente fragmentación política; emergencia de los centros locales y sus rasgos particulares; reconfiguración de los contactos con el exterior y emergencia de prácticas sociopolíticas subyacentes. 
Ahora bien, luego de reflexionar acerca del uso que se hizo tradicionalmente de las narrativas tardías para explicar tales procesos, se propuso una actualización de las cuestiones más relevantes que hoy en día se discuten sobre los mismos, lo cual refuerza la singularidad que define a cada uno de ellos.

Por cierto, se puede realizar una síntesis definitoria de los Períodos Intermedios caracterizándolos como situaciones ideales para visualizar la emergencia de prácticas y particularidades locales que suelen permanecer subsumidas bajo el paraguas del Estado unificado, cuando rige la autoridad de un único rey. Así, en tales procesos es factible evidenciar la emergencia de "lo local" en lo que hace a la cultura material, pero también en cuanto a prácticas comunitarias; mostrar la competencia por el acceso a la cúspide del poder por parte de las diversas elites y revelar fenómenos relativos a la construcción de sus identidades; visualizar los modos en que se integran los lazos intra e inter-élites a través de prácticas como el parentesco y el patronazgo; y detectar la relevancia que poseen los circuitos de circulación de bienes. Por cierto, este breve listado no agota los fenómenos pasibles de ser visualizados y estudiados en profundidad en esos lapsos disruptivos, pero valida la complejidad y singularidad emergente de cada uno de ellos. 


\section{Q Bibliografía}

»Abercrombie, N. y Hill, S. (1976). Paternalism and Patronage, en: British Journal of Sociology 27/4: 413-429.

» Adams, M. J. (2011). Manetho's Twenty-Third Dynasty and the Legitimization of Kushite Rule over Egypt, en: Antiguo Oriente 9: 19-46.

»Adams, M. J. (2017). Egypt and the Levant in the Early to Middle Bronze Age Transition, en: Höflmayer, F. (ed.), The Late Third Millennium in the Ancient Near East. Chronology, $\mathrm{C}_{14}$, and Climate Change, (Oriental Institute Seminar, 11). Chicago (IL): The University of Chicago, 493-515.

"Assmann, J. (2002). The Mind of Egypt. History and Meaning in the Time of the Pharaohs. Cambridge (MA) \& Londres: Harvard University Press.

»Bell, B. (1971). The Dark Ages in Ancient History. I. The First Dark Age in Egypt, en: American Journal of Archaeology 75/1: 1-26.

" Bietak, M. (1996). Avaris. The Capital of the Hyksos. Recent Excavations at Tell elDab'a. Londres: British Museum Press.

"Bietak, M. (2010). From Where Came the Hyksos and Where Did They Go?, en: Marée, M. (ed.), The Second Intermediate Period (Thirteenth-Seventeenth Dynasties). Current Research, Future Prospects, (Orientalia Lovaniensia Analecta, 192). Lovaina: Peeters, 139-182.

»Broekman, G. (2010). Libyan Rule over Egypt. The Influence of the Tribal Background of the Ruling Class on Political Structures and Developments during the Libyan Period in Egypt, en: Studien zur Altägyptischen Kultur 39: 85-99.

»Campagno, M. (2011). Lo patronal, lo estatal y lo parental en la Autobiografía de Ankhtifi de Mo'alla, en: Antiguo Oriente 9: 85-101.

»Campagno, M. (2013). De crisis y colapsos. Problemas de historiografía e historia del valle del Nilo hacia finales del III milenio a.C., en: XIV Jornadas Interescuelas/ Departamentos de Historia. Departamento de Historia de la Facultad de Filosofía y Letras. Universidad Nacional de Cuyo, Mendoza. Recuperado de http://cdsa. aacademica.org/ooo-010/37.pdf

»Cervelló Autuori, J. (1996). Egipto y África: origen de la civilización y la monarquía faraónicas en su contexto africano. Sabadell: AUSA.

»Crespo, C. (2011). Egipto bajo los reyes y jefes de origen libio (Tercer Período Intermedio): Algunas observaciones respecto de sus prácticas políticoceremoniales, en: Antiguo Oriente 9: 119-134.

"Daneri de Rodrigo, A. (1992). Las dinastías VII-VIII y el período heracleopolitano en Egipto. Problemas de reconstrucción histórica de una época de crisis, (Anexos de la Revista de Estudios de Egiptología, Colección Estudios, 3). Buenos Aires: CONICET.

»David, A. (200o). De l'infériorité à la perturbation: l'oiseau du «mal» et la catégorisation en Egypte ancienne, (Göttinger Orientforschungen IV: Reihe Ägypten, 38). Wiesbaden: Harrassowitz Verlag.

»Dee, M. W. (2017). Absolutely Dating Climatic Evidence and the Decline of Old Kingdom Egypt, en: Höflmayer, F. (ed.), The Late Third Millennium in the Ancient 
Near East. Chronology, C14, and Climate Change, (Oriental Institute Seminar, 11). Chicago (IL): The University of Chicago, 323-331.

»Depuydt, L. (1993). The Date of Piye's Egyptian Campaign and the Chronology of the Twenty-Fifth Dynasty, en: Journal of Egyptian Archaeology 79: 269-274.

"Enmarch, R. (2008). A World Upturned. Commentary on an Analysis of The Dialogue of Ipuwer and the Lord of All. Oxford: Oxford University Press.

»Eisendstadt, S. N. y Roniger, L. (1980). Patron-Client Relations as a Model of Structuring Social Exchange, en: Comparative Studies in Society and History 22/1: 42-77.

» Finkelstein, I. y Silberman, N. A. (2003 [2001]). La Biblia desenterrada. Una nueva visión arqueológica del antiguo Israel y de los orígenes de sus textos sagrados. Madrid: Siglo XXI.

» Flammini, R. (2013). Élites emergentes en el sistema-mundo nilótico-levantino: prácticas de legitimación de la dinastía de los Hicsos (ca. 1640-1530 a.C.), en: Di Bennardis, C., Milevski, I. y Ravenna, E. (eds.), Diversidad de formaciones políticas en Mesopotamia y el Cercano Oriente. Organización interna y relaciones interregionales en la Edad del Bronce, (Barcino Orientalia Monographica, 1). Barcelona: IPOA, 165-191.

"Flammini, R. (2016). Disrupción en el sistema-mundo nilótico-levantino c. 1800-1530 a.C., en: Flammini, R. y Tebes, J. M. (eds.), Interrelaciones e identidades culturales en el Cercano Oriente Antiguo. Buenos Aires: CONICET, $125-157$.

» Franke, D. (2006). Fürsorge und Patronat in der Erstern Zwischenzeit und in Mittleren Reich, en: Studien zur Altägyptischen Kultur 34: 159-185.

» Gabolde, L. (2005). Une trosième stèle de Kamosis?, en: Khyphi 4: 35-42.

»Gardiner, A. (1916). The Defeat of the Hyksos by Kamōse: The Carnarvon Tablet, No. I, en: Journal of Egyptian Archaeology 3: 95-110.

» Gardiner, A. (1969 [1909]). The Admonitions of an Egyptian Sage from a Hieratic Papyrus in Leiden (Pap. Leiden 344 Recto). Hildesheim: Georg Olms Verlag.

" Grimal, N.-C. (1981). La stèle triomphale de Pi('ankh)y au Musée du Caire:JE 48862 et 47086-47089. El Cairo: Institut français d'archéologie orientale.

" Habachi, L. (1972). The Second Stela of Kamose and his Struggle against the Hyksos Ruler and his Capital, (Abhandlungen des Deutschen Archaölogischen Instituts Kairo). Glückstadt: J.J. Augustin.

» Hafsaas-Tsakos, H. (2008). Between Kush and Egypt. The C-Group People of Lower Nubia during the Middle Kingdom and Second Intermediate Period, en: Godlewski, W. y Łajtar, A. (eds.), Between the Cataracts. Proceedings of the 11th International Conference for Nubian Studies, Warsaw University, 27 August-2 October 2006, (PAM Supplement Series, 2.2). Varsovia: The Polish Center of Mediterranean Archaeology, 389-396.

" Heimpel, W. (2003). Letters to the King of Mari. A New Translation with Historical Introduction, Notes and Commentary. Winona Lake (IN): Eisenbrauns.

» Helck, W. (1970). Die Prophezeiung des Nfr.tj. Wiesbaden: Harrassowitz.

»Hsu, S.W. (2010). The Palermo Stone: the Earliest Royal Inscription from Ancient Egypt, en: Altorientalische Forschungen 37/1: 68-89.

» Kitchen, K. (1969-70). Two Donation Stelae in the Brooklyn Museum, en: Journal of the American Research Center in Egypt 8: 59-67. 
》 Koselleck, R. (2004 [1985]). Futures Past. On the Semantics of Historical Time. Nueva York: Columbia University Press.

»Khótay, K. (2013). Categorisation, Classification, and Social Reality: Administrative Control and Interaction with the Population, en: Moreno García, J. C. (ed.), Ancient Egyptian Administration, (Handbuch der Orientalistik Section, 1, Ancient Near East). Leiden: Brill, 479-520.

» Lacau, P. (1939). Une stèle du roi 'Kamosis', en: Annales du Service des Antiquités de l'Egypte 39: 245-271.

"Leahy, A. (1985). The Libyan Period in Egypt. An Essay in Interpretation. Londres: The Society for Libyan Studies.

»Lemche, N.P. (1993). The Old Testament-An Hellenistic Book?, en: Scandinavian Journal of the Old Testament 7: 163-193.

» Lichtheim, M. (1973). Ancient Egyptian Literature, vol. I: The Old and Middle Kingdoms. Berkeley: University of California Press.

» Lichtheim, M. (1980). Ancient Egyptian Literature, vol. III: Late Period. Berkeley: University of California Press.

» Lichtheim, M. (1988). Ancient Egyptian Autobiographies chiefly of the Middle Kingdom. A Study and an Anthology, (Orbis Biblicus et Orientalis, 84). Gotinga: Vandenhoeck \& Ruprecht.

»Lloyd, A. (2014a). Ancient Egypt. State and Society. Oxford: Oxford University Press.

»Lloyd, A. (2014b). The Egyptian Attitude to the Persians, en: Dodson, A., Johnston, J. J. y Monkhouse, M. (eds.), A Good Scribe and an Exceedingly Wise Man: Studies in Honour of W. J. Tait. Londres: Golden House Publications, 185198.

»Meeks, D. (2009). Une stèle de donation de la Deuxième Période Intermédiaire, en: Égypte Nilotique et Méditerranée 2: 129-154.

»Menu, B. (1998). Recherches sur l'histoire juridique, économique et sociale de l'ancienne Égypte, II, (Bibliothèque d'étude, 122). El Cairo: Institut français d'archéologie orientale.

"Meyer, E. (1884-1902). Geschichte des Altertums. Sttutgart: J. G. Motta.

»Moeller, N. y Marouard, G. (with a contribution by N. Ayers). (2011). Discussion of Late Middle Kingdom and Early Second Intermediate Period History and Chronology in Relation to the Khayan Sealings from Tell Edfu, en: Ägypten und Levante XXI: 87-121.

» Moreno García, J. C. (1997). Études sur l'administration, le pouvoir et l'ideologie en Égypte, de l'Ancien au Moyen Empire, (Aegyptiaca Leodinensia, 4). Lieja: CIPL.

» Moreno García, J. C. (2009). Egipto en el Segundo Período Intermedio (1773-1550 a.C.), en: Parra, J. M. (coord.), El Antiguo Egipto. Sociedad, economía, política. Madrid: Marcial Pons, 273-300.

»Moreno García, J. C. (2013a). The Territorial Administration of the Kingdom in the 3rd Millennium, en: Moreno García, J. C. (ed.), Ancient Egyptian Administration, (Handbuch der Orientalistik Section, 1, Ancient Near East). Leiden: Brill, 85-161.

» Moreno García, J. C. (2013b). The ‘Other’ Administration: Patronage, Factions, and Informal Networks of Power in Ancient Egypt, en: Moreno García, J. C. (ed.), Ancient Egyptian Administration, (Handbuch der Orientalistik Section, 1, Ancient 
Near East). Leiden: Brill, 1029-1065.

" O'Connor, D. (1990). The Nature of Tjemhu (Libyan) Society in the Later New Kingdom, en: Leahy, A. (ed.), Libya and Egypt: c. 1300-750 BC. Londres: Centre of Near and Middle Eastern Studies and Society for Libyan Studies, School of Oriental and African Studies, 29-113.

"Pfoh, E. (2009). The Emergence of Israel in Ancient Palestine: Historical and Anthropological Perspectives. Copenhagen International Seminar. Londres: Equinox.

" Quirke, S. (1991). Royal Power in the 13th Dynasty, en: Quirke, S. (ed.), Middle Kingdom Studies. New Malden: SIA Publishing, 123-139.

» Riggs, Ch. y Baines, J. (2012). Ethnicity, en: Frood, E. y Wendrich, W. (eds.), UCLA Encyclopedia of Egyptology. Los Angeles. Recuperado de http://digital2.library. ucla.edu/viewltem.do?ark=21198/zzoo $2 \mathrm{bpmfm}$

» Ritner, R. K. (2009). The Libyan Anarchy. Inscriptions from Egypt's Third Intermediate Period, (Writings from the Ancient World, 21). Atlanta (GA): Society of Biblical Literature.

》 Rosell, P. (2015). La representación de las élites egipcias en las Admoniciones de Ipuwer, en: Antiguo Oriente 13: 199-220.

" Ryholt, K. (1997). The Political Situation in Egypt during the Second Intermediate Period c. 1800-1550 BC. Copenhague: Museum Tusculanum Press.

» Ryholt, K. (2004). The Turin King-List, en: Ägypten und Levante XIV: 135-155.

"Schloen, J. D. (2017). Economic and Political Implications of Rising the Date for the Disappearance of Walled Towns in the Early Bronze Age Southern Levant, en: Höflmayer, F. (ed.), The Late Third Millennium in the Ancient Near East. Chronology, C14, and Climate Change, (Oriental Institute Seminar, 11). Chicago (IL): The University of Chicago, 59-71.

"Schneider, T. (2017). 'What Is the Past but a Once Material Existence Now Silenced?' The First Intermediate Period from an Epistemological Perspective, en: Höflmayer, F. (ed.), The Late Third Millennium in the Ancient Near East. Chronology, C14, and Climate Change, (Oriental Institute Seminar, 11). Chicago (IL): The University of Chicago, 311-322.

"Schneider, T. (2018). Khyan's Place in History. A New Look at the Chronographic Tradition, en: Forstner-Müller, I. y Moeller, N. (eds.), The Hyksos Ruler Khyan and the Early Second Intermediate Period in Egypt: Problems and Priorities of Current Research. Proceedings of the Workshop of the Austrian Archaeological Institute and the Oriental Institute of the University of Chicago, Vienna, July 4 - 5, 2014. (Ergänzungshefte zu den Jahresheften des Österreichischen Archäologischen Institutes, Heft 17). Viena: Österreichische Akademie der Wissenschaften, 277-284.

"Seidlmayer, S. J. (2003 [2000]). The First Intermediate Period (2160-2055 BC), en: Shaw, I. (ed.), The Oxford History of Ancient Egypt. Londres: Oxford University Press, 108-136.

» Smith, H. y Smith, A. (1976). A Reconsideration of the Kamose Texts, en: Zeitschrift für Ägyptische Sprache und Altertumskunde 103: 48-76.

"Spalinger, A. (2008). Chauvinism in the First Intermediate Period, en: Vymazalová, H. y Barta, M. (eds.), Chronology and Archaeology in Ancient Egypt (The Third Millennium BC). Praga: Czech Institute of Egyptology, 240-26o. 
» Spalinger, A. (2010). Two Screen Plays: 'Kamose' and 'Apophis and Seqenenre', en: Journal of Egyptian History 3: 115-135.

» Taylor, J. (2003 [2000]). The Third Intermediate Period (1069-664 BC), en: Shaw, I. (ed.), The Oxford History of Ancient Egypt. Londres: Oxford University Press, 324-363.

» Tobin, V. (2003 [1973]). The Admonitions of an Egyptian Sage, en: Simpson, W. K. (ed.), The Literature of Ancient Egypt: An Anthology of Stories, Instructions and Poetry. New Haven: Yale University Press, 188-210.

»Van De Mieroop, M. (2011). A History of Ancient Egypt, (Blackwell History of the Ancient World). West Sussex: Wiley-Blackwell.

»Van Siclen III, C. (2005). Conservation of the Third Kamose Stela at Karnak (Phase I), en: Bulletin of the American Research Center in Egypt 188: 21-23.

"Van Siclen III, C. (2010). The Third Stela of Kamose, en: Marée, M. (ed.), The Second Intermediate Period (Thirteenth-Seventeenth Dynasties). Current Research, Future Prospects, (Orientalia Lovaniensia Analecta, 192). Lovaina: Peeters, 355365.

" van Walsen, R. (1992). The Usurpation of Royal and Divine Actions and/or Attributes in the Iconography of the Late 21st-Early 22nd Dyn. Coffins, en: AA.VV., Atti del VI Congresso Internazionale di Egittologia, I. Turín: International Association of Egyptologists, 643-649.

»Vandier, J. (1950). Mo'alla. La tombe d'Ankhtifi et la tombe de Sébekhotep. El Cairo: Institut français d'archéologie orientale.

»Vercoutter, J. (1998). Koummeh-Semneh. L'occasion perdue, en: Cahier de Recherches de l'Institut de Papyrologie et Egyptologie de Lille 19: 35-42.

"Waddell, W. G. (trad.). (1940). Manetho (Loeb Classical Library). Cambridge (MA): Harvard University Press / Londres: Heinemann.

»Wegner, J. y Cahail, K. (2014). Ancient Reuse: The Discovery of a Royal Sarcophagus Chamber, en: Expedition 56/1: 19-23.

»Wegner, J. (2014). Discovering Pharaohs Sobekhotep \& Senebkay: An Update from the 2013-2014 Field Season, en: Expedition 56/1: 39-41.

»White, H. (2002). Foreword, en: Koselleck, R. (ed.), The Practice of Conceptual History. Timing History, Spacing Concepts, (Cultural Memory in the Present). Stanford: Stanford University Press.

»Wilkinson, T. (2017). Writings from Ancient Egypt. Londres: Penguin Books.

» Yoffee, N. (1993). Too Many Chiefs? (or, Safe Texts for the '90s), en: Yoffee, N. y Sherratt, A. (eds.), Archaeological Theory: Who Sets the Agenda? Cambridge (UK): Cambridge University Press, 60-78. 